\title{
Permeation and Blockage of Fine Particles Transported by Updraft through a Packed Bed (Numerical Approach)
}

\author{
Shin SATOU, ${ }^{1)}$ Siahaan Andrey STEPHAN, ${ }^{2) *}$ Yoshihiko OISHI, ${ }^{2)}$ Hideki KAWAIl) and Hiroshi NOGAMI ${ }^{3)}$ \\ 1) National Institute of Technology, Tomakomai College, 443 Nishikioka, Tomakomai, Hokkaido, 059-1275 Japan. \\ 2) Graduate School of Engineering, Muroran Institute of Technology, 27-1 Mizumoto, Muroran, Hokkaido, $050-8585$ Japan. \\ 3) Institute of Multi-disciplinary Research for Advanced Materials, Tohoku University, 2-1-1, Katahira, Sendai, $980-8577$ Japan.
}

(Received on February 27, 2020; accepted on April 9, 2020)

\begin{abstract}
As a method for reducing $\mathrm{CO}_{2}$ in blast furnaces, low-reducing agent ratio and large amount of pulverized coal is being carried out to reduce the amount of coke used and reduce the carbon input to the blast furnace and its operation cost. However, these operating methods increase the deposit amount of coke powder and unburned char generated in the blast furnace and decrease process efficiency. A threedimensional numerical model is built and observed by the coupling system of DEM-CFD, performed to understand the principal factors that affected fine and gas permeability. Simulation is carried out in, where fine particles are injected simultaneously from the bottom of cylindrical packed bed, mimicking the experimental approach. The fine to packed diameter ration is given by $0.133 \leq \mathrm{Dp} / \mathrm{dp} \leq 0.162$. At a larger diameter ratio, fine particles tend to concentrate at the bottom of the packed bed. In the case of lower particle diameter ratio, updraft gas will easy to permeate along with fine particles because of the existing of large open flow channels relative to fine diameter. Furthermore, no significant change in fine fraction transported to the upper area due to the change of gas velocities. In this present study, the effect of continuous fine particles injection and its effect on gas flow can be observed, where the gas flow avoiding the heavily concentrated area.
\end{abstract}

KEY WORDS: blast furnace; packed bed; DEM-CFD; continuous fine injection; blockage.

\section{Introduction}

In recent years, shifting trend in the iron making process, where the large supply of pulverized coal at tuyere directed at the low reducing agents rate. ${ }^{1)}$ This kind of operation is increasing in demands, however, it has the problem at agitated or unsteady behavior inside the blast furnace. Therefore, there is large growth demand in analyses about the fines deposited locally in iron making blast furnace and its influence on gas permeability inside that caused inhomogeneous flow. ${ }^{2)}$

Some experimental researches regarding the interactions between pressure drop and updraft gas inside the packed bed already been done. Hidaka et al. $^{3-6)}$ performed investigations on the effect of inlet gas velocity, fine particles morphology, and packed bed model and the effect of these to static and dynamic holdup in the packed bed. Another experimental approach by Dong et al., ${ }^{7}$ conducted to understand the flow and accumulation behavior of powder in system like an ironmaking blast furnace. Similar to previous research, Dong et al. stated that fines accumulation behavior is affected by inlet gas velocity, fines mass flux. Moreover, the existence of impermeable blocks inside the packed bed, and packing model of fine particles was added

\footnotetext{
* Corresponding author: E-mail: andrey_si@yahoo.com DOI: https://doi.org/10.2355/isijinternational.ISIJINT-2020-108
}

as new parameters. Chen et al. ${ }^{8)}$ Pham et al. ${ }^{9)}$ and Shibata et al. ${ }^{10)}$ mainly focused in the investigation on the effect of powder mass flux and low gas velocity effect towards pressure drops inside the packed bed. It was found that pressure drop inside the packed bed will decrease with the decrease of gas velocity. However, further decrease will lead to the increase of pressure drop because of the rapid accumulation of fine particles. Takahashi et al. ${ }^{11)}$ conducted a study on permeation and blockage of fine particles transported by updraft through the packed bed. This study mainly focused on the effect of fines to packed diameter ratio, updraft gas velocity, fines mass flux, and gas inlet velocities on clogging formation and gas permeability inside the packed bed. From this study, they proposed critical fines to packed diameter ratio of $0.11-0.12$.

Studies regarding permeation and blockage behavior of fine flow characteristics inside the packed bed regarding the gas and fines habitual character are found to be exacting to inspect fines distribution because the inner part of packed bed is difficult to be observed directly. In recent years, advances in computing speed and power as well as improvements in programming have the way to open more understanding of modeling complex granular flow using discrete element method (DEM). This particulate system modeled as an assembly of singular discrete and interacting particles with its interactions towards gas flow using computational fluid dynamics (CFD). Some approaches on 
the method of DEM-CFD coupling is already been investigated. Chu and $\mathrm{Yu},{ }^{12)}$ presented numerical study regarding complex particle-fluid flow using combined continuum and discrete method in various 3D systems such as pneumatic conveying bend, cyclone separator, and circulating fluidized bed. This numerical approach was able to capture key flow features that affected in the experimental approach of each system, such as axial solid segregation, shaped profile in the axial solid distributions, and annulus core flow structure that causes solid back mixing. Dong et al., ${ }^{13)}$ developed mathematical model to describe the gas-powder two-phase flow in a packed bed. The calculated results show that the large difference in physical properties is the main factor responsible for the different flow behavior between gas and powder phases. Furthermore, similar to their experimental results, ${ }^{7)}$ powder accumulation region also identified in low gas velocity. Xu et al., ${ }^{14)}$ and Matsuhashi et al., ${ }^{15)}$ conducted simulation on the effect of the lateral gas inlet to bed transformations from fixed bed to fluidized bed and vice versa. Nogami et al. ${ }^{16)}$ was able to identify that voidage takes more on permeability of the high temperature gas than coke diameter inside the blast furnace. Kikuchi et al. ${ }^{17)}$ investigated wall effect, powder morphologies, and inlet gas velocity to voidage and blockage formation in packed bed of blast furnace. Natsui et al., ${ }^{18)}$ using the DEM-CFD approach to simulate the physical condition of previous research. ${ }^{11)}$ Natsui et al. was able to show local blockage and cluster formation in the transition area between the test section bed and additional packed bed. However, because of time consuming calculation, the numerical model only lasts for $1.5 \mathrm{~s}$ in previously reported paper, where a large amount of fine particles is injected in one time to abridge the blockage formation behavior, thus the pressure distribution inside the bed between the numerical and experimental one cannot be compared.

The objective of this study is to clarify blockage formation and permeability criterion of fine particles due to the obstructing effect of updraft gas and fines to packed bed diameter ratio. Fine particles are injected continuously, with constant feed rate in regards to mimic the experimental conditions. ${ }^{11)}$ The numerical model is built and observed by coupling system of DEM-CFD. With the purposed model, it is possible to compare pressure distribution inside the packed bed due to resemblance conditions between experimental and numerical approaches. Moreover, some oddity in fine hold up also can be observed from this model of continuous feed rate and its relation with various velocities of updraft gas.

\section{Governing Equation and Numerical Method}

In this study, gas-powder two-phase flow analysis was performed using fluid and powder analysis software "R-flow". In this section, the analysis method of particles and fluid behaviors, also the method for coupling analysis of these two analyses method, will be explained.

\subsection{Discrete Element Method (DEM) Analyses}

The discrete element method (DEM) is a discrete assembly, where individual components satisfy the equation of motion and the transfer of force with other components and obeys the law of action and reaction.

In the numerical analysis of dynamic behavior in moving and fluidized beds, powder particles flowing as a group of many particles while the particles move and collide with adjacent particles and walls. Based on Newton's second law of motion, equations of motion for translational and rotational motion of a particle are described as follows:

$$
\begin{gathered}
m_{\mathrm{p}}=\frac{d \vec{v}_{\mathrm{p}}}{d t}=\vec{F}+m \vec{g} \\
I_{\mathrm{p}} \frac{d \omega_{\mathrm{p}}}{d t}=r_{\mathrm{p}} \vec{F} \ldots
\end{gathered}
$$

Here, $m_{\mathrm{p}}$ is particle mass $[\mathrm{kg}], v_{\mathrm{p}}$ is particle velocity $\left[\mathrm{m} \mathrm{s}^{-1}\right], t$ is time [s], $F$ is external force which includes contact force and drag force $[\mathrm{N}], g$ is gravity $\left[\mathrm{m} \mathrm{s}^{-2}\right], I \mathrm{p}$ is particle moment of inertia $\left[\mathrm{kg} \mathrm{m}^{2}\right], \omega_{\mathrm{p}}$ is particle angular velocity $\left[\mathrm{rad} \mathrm{s} \mathrm{s}^{-1}\right], r_{\mathrm{p}}$ is particle radius $[\mathrm{m}]$. Focusing on one isolating pair of particle interaction of existing external force shown in Fig. 1(a). Particle movement is affected by the force and gravity due to the contact with the surrounding objects. The collision between particles is considered inelastic, which means kinetic energy is dissipated during the collision. The collision model is expressed by the Voigt model, consist of spring and dashpot shown in Fig. 1(b). The spring represents the repulsive forces when particles are in contact, and the dashpot represents subsided kinetic energy. To consider the friction between particles and between particles and the wall, a friction slider is added to the model of

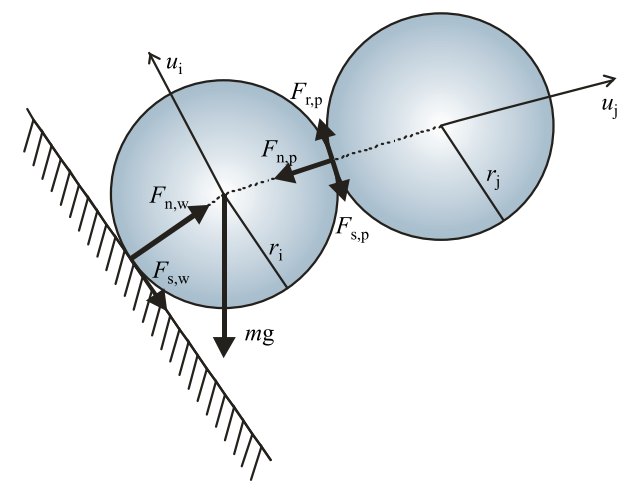

(a) Contact forces of particles $\mathrm{i}$ and $\mathrm{j}$

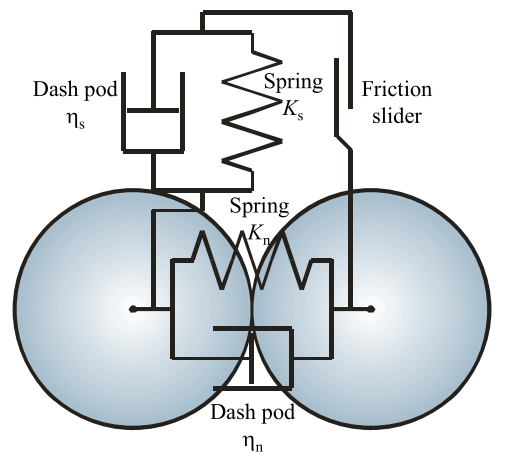

(b) Voigt Model

Fig. 1. Analysis model. (Online version in color.) 
rotational movement.

When a particle collides, a small deformation occurs, where a contact force corresponding to the amount of deformation and the rate of deformation is generated. The contact force acting between two particles in the Voigt model is described by the following equation, where $u$ is the translational displacement of the particle [m], and $\phi$ is the rotational displacement [rad], expressed in equations below:

$$
\begin{aligned}
& m_{i} \frac{d^{2} u_{i}}{d t^{2}}+\eta \frac{d u_{i}}{d t}+K u_{i}=0 \\
& I_{i} \frac{d^{2} \phi_{i}}{d t^{2}}+\eta \frac{d \phi_{i}}{d t}+K r^{2} \phi=0
\end{aligned}
$$

Here, $K$ is the spring constant $\left[\mathrm{N} \mathrm{m}^{-1}\right]$ and $\eta$ is damping coefficient $\left[\mathrm{kg} \mathrm{s}^{-1}\right]$. As particle is in contact with another particle, Eqs. (3) and (4) corresponds to each contact point. The acceleration of the target particle calculated by integrating the contact forces at all the contact points and substituting them into Eqs. (1) and (2).

Since the contact force between particles acts in various directions, it is the combined force of the direction (normal direction $\mathrm{n}$ ) perpendicular to the particle tangent plane and the direction of the particle tangent plane (shear direction s1, s2), where $F$ is contact force [N], expressed by Eq. (5). The contact force is consist of normal force expressed by $F_{\mathrm{n}}$ and shear force $F_{\mathrm{s}}$, expressed by Eqs. (6) and (7), respectively.

$$
\begin{aligned}
& F=F_{\mathrm{n}}+F_{\mathrm{s}} \\
& F_{\mathrm{n}}=-K_{\mathrm{n}} \Delta u_{\mathrm{n}}-\eta \frac{\Delta u_{\mathrm{n}}}{\Delta t} \\
& F_{\mathrm{s}}=\left(\begin{array}{l}
F_{\mathrm{s} 1} \\
F_{\mathrm{s} 2}
\end{array}\right)=\left(\begin{array}{l}
-K_{\mathrm{n}} \Delta u_{\mathrm{s} 1}-\eta_{\mathrm{n}} \frac{\Delta u_{\mathrm{s} 1}}{\Delta t} \\
-K_{\mathrm{n}} \Delta u_{\mathrm{s} 2}-\eta_{\mathrm{n}} \frac{\Delta u_{\mathrm{s} 2}}{\Delta t}
\end{array}\right) \cdots
\end{aligned}
$$

\subsection{DEM-CFD Couplings Analyses Method}

The following momentum conservation law and continuity equation are used as coupling formula for fluid in gaspowder two-phase flow.

$$
\begin{gathered}
\alpha_{\mathrm{f}} \rho_{\mathrm{f}}\left(\frac{\partial V_{\mathrm{f}}}{\partial t}+\left(V_{\mathrm{f}} \cdot \nabla V_{\mathrm{f}}\right)\right)=-\alpha_{\mathrm{f}} \nabla p+\alpha_{\mathrm{f}}\left(\rho_{\mathrm{f}}-\rho E_{\mathrm{f} 0}\right) g \\
+\alpha_{\mathrm{f}} \alpha_{\mathrm{p}} \beta\left(V_{\mathrm{p}}-V_{\mathrm{f}}\right)+\nabla \cdot\left(\alpha_{\mathrm{f}} \mu_{\mathrm{f}} \nabla V_{\mathrm{f}}\right) \\
\frac{\partial \alpha_{\mathrm{f}}}{\partial t}+\nabla \cdot\left(\alpha_{\mathrm{f}} \cdot V_{\mathrm{f}}\right)=0 \ldots \ldots \ldots \ldots \ldots \ldots \ldots \ldots \ldots \ldots \ldots \ldots \ldots
\end{gathered}
$$

The subscripts $f$ and $p$ indicate physical quantities of fluid and powder particles, where $f$ represent the fluid part and $\mathrm{p}$ represent the particle part respectively, and $\alpha_{\mathrm{f}}+\alpha_{\mathrm{p}}=1 . \beta$ represents the momentum exchange coefficient between the continuous phase and the dispersed phase. $\rho_{\mathrm{fo}}$ is the reference density to the pressure $\mathrm{p}$ and the deviation pressure from hydrostatic pressure $\left[\mathrm{kg} \mathrm{m}^{-3}\right]$, when the density $\rho_{\mathrm{f}}$ of the continuous phase is constant, noted as $\rho_{\mathrm{f} 0}=\rho_{\mathrm{f}}$. For the drag coefficient, Ergun's drag model for solid particles is use as shown in Eqs. (10) to (15).

$$
\begin{aligned}
& \beta=\beta_{1} \quad\left(\alpha_{\mathrm{f}} \leq 0.8\right) \\
& \beta=\beta_{2} \quad\left(\alpha_{\mathrm{f}}>0.8\right) \\
& \beta_{1}=\frac{150 \alpha_{\mathrm{p}} \mu_{\mathrm{f}}}{\left(\alpha_{\mathrm{f}} d_{\mathrm{p}}\right)^{2}}+\frac{1.75\left|V_{\mathrm{p}}-V_{\mathrm{f}}\right| \rho_{\mathrm{p}}}{\left(\alpha_{\mathrm{f}} d_{\mathrm{p}}\right)} \quad\left(\alpha_{\mathrm{f}} \leq 0.8\right) \ldots . . \\
& \beta_{2}=\frac{0.75 C_{\mathrm{D}} \rho_{\mathrm{f}}\left|V_{\mathrm{p}}-V_{\mathrm{f}}\right|}{\left(d_{\mathrm{p}} \alpha_{\mathrm{f}}^{2.7}\right)} \quad\left(\alpha_{\mathrm{f}}>0.8\right) \\
& C_{\mathrm{D}}=\max \left(\frac{24\left(1+0.15 \mathrm{Re}_{\mathrm{p}}^{0.687}\right)}{\operatorname{Re}_{\mathrm{p}}}, 0.44\right) \ldots \ldots \ldots \\
& \operatorname{Re}_{\mathrm{p}}=\frac{\rho_{\mathrm{f}}\left|V_{\mathrm{p}}-V_{\mathrm{f}}\right| d_{\mathrm{p}}}{\mu_{\mathrm{f}}}
\end{aligned}
$$

\subsection{Numerical Conditions and Analyses}

The calculation domain for the numerical model is set based on the experimental apparatus used in the literature, ${ }^{11)}$ and it is shown in Fig. 2(a). The domain consists of a conical diffuser bed which bottom diameter and height are of 40 and $51.96 \mathrm{~mm}$, respectively, and a vertical circular column of which diameter and height are 100 and 530 $\mathrm{mm}$, respectively. Beneath the column, a cone-shaped diffuser which is filled with glass beads of $12 \mathrm{~mm}$ is settled. In the experiments, the column was filled with particle, and the gas-powder two phase flow is introduced from the bottom through the diffuser. The vertical pressure distribution was measured by the pressure sensors settled every $120 \mathrm{~mm}$. The sections between sensors are designated as P1, P2 and P3 from the lower position and the pressure drops in these sections are expressed as $\Delta p_{1}, \Delta p_{2}$, and $\Delta p_{3}$, respectively. Figure 2(b) shows the grid arrangement used in the numerical simulation. Two types of packed beds are formed according to the literature. ${ }^{11)}$ In model A, shown in Fig. 2(c), the column is filled with only alumina particles while the diffuser bed exists at the bottom part. This top filled section is the test section. In model B, shown in Fig. 2(d), a packed bed of which height is $120 \mathrm{~mm}$ is formed with particles of $8 \mathrm{~mm}$ in diameter on the top of the diffuser bed, and this part is called the extra bed, hereinafter. Then the remaining part of the bed is filled with alumina particles and it is treated as the test section. In this paper, the bottom part of the alumina bed, with $50 \mathrm{~mm}$ in height is called the transition area. The powder behaviors in the transition area will be discussed later. After the packed bed is formed in the vertical column, the fine particles and gas are injected simultaneously from the bottom of the domain at constant rates for 30 seconds.

In the simulation, the packed beds of the alumina beads, extra bed, and diffuser are treated as fixed beds because the fluid drag and the contact force from the fine particles are small enough to move packed particles. Three combinations of the fine particles and the alumina particles are examined. In case 1 , the fine particles with diameter of $0.388 \mathrm{~mm}$ are injected into packed bed model $\mathrm{A}$, of alumina beads with 

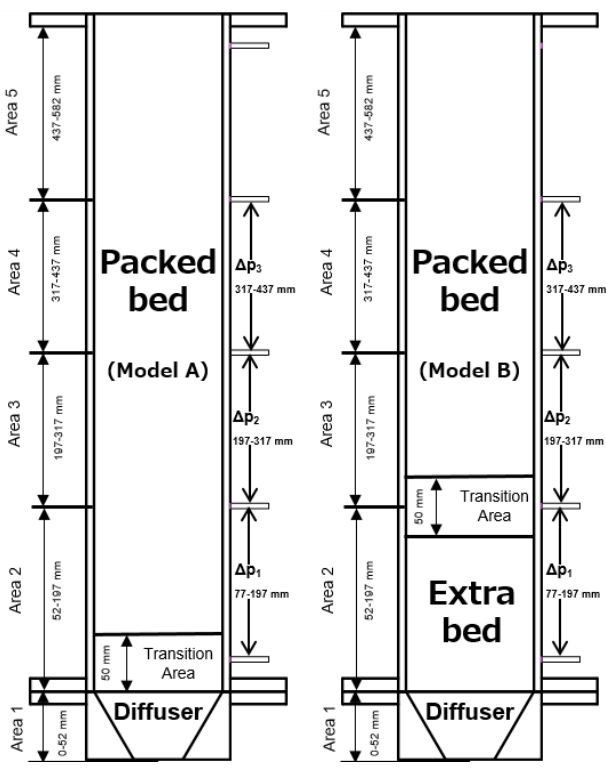

(a)

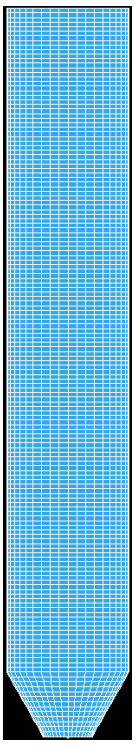

(b)

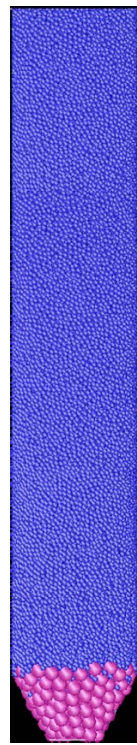

(c)

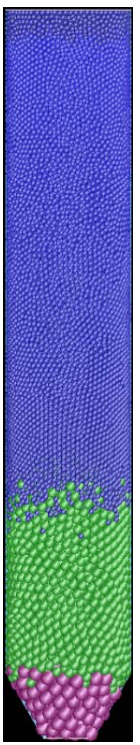

(d)

Fig. 2. (a) Strain gauge position and area positions of each model (b) calculation domain (c) model A (d) model B. (Online version in color.)

diameter $2.6 \mathrm{~mm}$. In this condition, the diameter ratio of the fine particles to the alumina beads $\left(d_{\mathrm{p}} / D_{\mathrm{p}}\right)$ is $0.149[-]$. The next two cases use model $\mathrm{B}$ and the fine particles with diameter $0.596 \mathrm{~mm}$. In case 2 , the alumina beads with diameter $4.48 \mathrm{~mm}\left(d_{\mathrm{p}} / D_{\mathrm{p}}=0.133\right)$ is used, and in case 3 , the alumina beads of $3.68 \mathrm{~mm}\left(d_{\mathrm{p}} / D_{\mathrm{p}}=0.162\right)$ is used. For the first three cases, the updraft gas velocity of $0.88 \mathrm{~m} \mathrm{~s}^{-1}$. The effect of updraft gas velocity will be discussed by using the same model as case 2 where the gas velocities are modified $\left(u_{\mathrm{f}}=1.06\left[\mathrm{~m} \mathrm{~s}^{-1}\right]\right.$ and $\left.u_{\mathrm{f}}=1.24\left[\mathrm{~m} \mathrm{~s}^{-1}\right]\right)$, and later called as case 4 and case 5 , respectively. The calculation conditions and the parameters for the numerical simulations are listed in Table 1.

For case 1 of packed bed model A, a constant mass of fines $\left(d_{\mathrm{p}}=0.388[\mathrm{~mm}] ; m_{\mathrm{f}}=0.059\left[\mathrm{~kg} \mathrm{~m} \mathrm{~m}^{-2} \mathrm{~s}^{-1}\right]\right)$ is fed to the diffuser at every second. For case 2 and $3\left(d_{\mathrm{p}}\right)$ $D_{\mathrm{p}}=0.133$ and $\left.d_{\mathrm{p}} / D_{\mathrm{p}}=0.162\right)$, of packed bed model B, a constant mass of fines $\left(d_{\mathrm{p}}=0.596[\mathrm{~mm}] ; m_{\mathrm{f}}=0.064[\mathrm{~kg}\right.$ $\left.\mathrm{m}^{-2} \mathrm{~s}^{-1}\right]$ ) are also fed the diffuser continuosly at every second. Furthermore, using the same parameter as case 2, the change of updraft gas velocity $\left(u_{\mathrm{f}}=1.06\left[\mathrm{~m} \mathrm{~s}^{-1}\right]\right.$ and $u_{\mathrm{f}}=$ $1.24\left[\mathrm{~m} \mathrm{~s}^{-1}\right]$ ) also will be discussed (cases 4 and 5). The gas-powder flow simulations are performed for $30.0 \mathrm{~s}$ of elapse of time and the powder feed rates are kept constant for this duration.

The conditions of this current study are determined based on the previous study with the same model of packed bed and flow rate. ${ }^{11)}$ As time lapses, fines hold up in the packed bed is increasing until the end of simulation time $(t=30$ $[\mathrm{s}])$. At this time, the total fines hold up for the case $1\left(d_{\mathrm{p}} /\right.$ $\left.D_{\mathrm{p}}=0.149[-]\right)$ is $0.142 \mathrm{vol} \%$, with the total fine particles are $48630[-]$, and for the cases 2 and $3\left(d_{\mathrm{p}} / D_{\mathrm{p}}=0.133\right.$ and 0.162 ), the total fines hold up is $0.162 \mathrm{vol} \%$, where the total fine particles is 14430 [-]. These values of fine particles hold ups are the average value of fine hold ups inside the packed bed and were obtained under the assumption that all fed fine particles stay in the packed bed. Indeed these
Table 1. Calculation conditions.

\begin{tabular}{|c|c|c|c|c|c|}
\hline \multirow[b]{2}{*}{ Diameter [mm] } & \multicolumn{3}{|c|}{$\begin{array}{l}\text { Alumina beads } \\
{\left[D_{\mathrm{p}}\right]}\end{array}$} & \multicolumn{2}{|c|}{$\begin{array}{l}\text { Fine particle } \\
\qquad\left[d_{\mathrm{p}}\right]\end{array}$} \\
\hline & 2.6 & 4.48 & 3.68 & 0.388 & 0.596 \\
\hline Density $\left[\mathrm{kg} \mathrm{m}^{-3}\right]$ & 1500 & 1106 & 1732 & \multicolumn{2}{|c|}{1369} \\
\hline Terminal Velocity $\left[\mathrm{m} \mathrm{s}^{-1}\right]$ & & - & & 2.06 & 3.15 \\
\hline Mass Flux $\left(m_{\mathrm{f}}\right)\left[\mathrm{kg} \mathrm{m}^{-2} \mathrm{~s}^{-1}\right]$ & & - & & 0.059 & 0.064 \\
\hline Particle Diameter Ratio [-] & \multicolumn{5}{|c|}{$0.133 ; 0.149 ; 0.162$} \\
\hline Dynamic Friction Coefficient & \multicolumn{3}{|c|}{0.7} & \multicolumn{2}{|c|}{1.0} \\
\hline Rolling Friction Coefficient & \multicolumn{3}{|c|}{0.7} & \multicolumn{2}{|c|}{0.7} \\
\hline Young Modulus [GPa] & \multicolumn{3}{|c|}{21} & \multicolumn{2}{|c|}{0.01} \\
\hline Poisson ratio & \multicolumn{3}{|c|}{0.24} & \multicolumn{2}{|c|}{0.21} \\
\hline Time Step $[\mathrm{s}]$ & \multicolumn{5}{|c|}{$1 \times 10^{-5}$} \\
\hline Fluid Density $\left[\mathrm{kg} \mathrm{m}^{-3}\right]$ & \multicolumn{5}{|c|}{1.2} \\
\hline Viscosity $[\mathrm{Pa} \cdot \mathrm{s}]$ & \multicolumn{5}{|c|}{$1.8 \times 10^{-5}$} \\
\hline $\begin{array}{c}\text { Gas Superficial Velocity }\left(u_{\mathrm{f}}\right) \\
{\left[\mathrm{m} \mathrm{s}^{-1}\right]}\end{array}$ & \multicolumn{5}{|c|}{$0.88 ; 1.06 ; 1.24$} \\
\hline Number of Grids $(h \times r \times \theta)$ & \multicolumn{5}{|c|}{$150 \times 12 \times 42$} \\
\hline Total Simulation time $[\mathrm{s}]$ & \multicolumn{5}{|c|}{30} \\
\hline
\end{tabular}

small amounts of fine hold up are quite smaller compare to the total volume of the packed bed, and cannot be applied to complete blockage. As a comparison, the simulation time and the total hold ups in this current study are much lower compared to each respective model of the experimental one. The total experimental time for each particle diameter ratio of $0.133,0.149$, and 0.162 , are 3630,255 , and 927 seconds, with the total hold ups of 24.7, 2.2, and $6.2 \mathrm{vol} \%$, respectively. However, due to continuous fines injection, it is expected to observe actual gas flow behavior and the initial stagnation of fine particles. Nevertheless, as 
the conditions of the previous study were recognized as experiment for the powder flow related to blast furnace, ${ }^{11)}$ and for this current study the same conditions such as flow rate of fine particles, packed arrangement, and void fraction are applied, therefore conditions of this current study should be acceptable to be related to fine particle flow condition in the blast furnace. Moreover, the pressure drop in three sections of $\mathrm{P} 1, \mathrm{P} 2$, and $\mathrm{P} 3$ of the three cases obtained from the numerical analysis will be compared to measured result ${ }^{11)}$ as validation.

\section{Results and Discussion}

\subsection{Numerical and Experimental Results Validation}

In this section, the pressure drops in the three sections P1, P2, and P3 under the updraft gas velocity of $0.88 \mathrm{~m} \mathrm{~s}^{-1}$ are compared. Figure 3 shows the comparison between measured and calculated pressure drops for the case 1 (packed bed model A, $d_{\mathrm{p}}=0.388[\mathrm{~mm}]$ and $\left.D_{\mathrm{p}}=2.60[\mathrm{~mm}]\right)$. Fine particles are injected continuously from the bottom of packed bed by a diffuser, with a constant rate at $0.059 \mathrm{~kg}$ $\mathrm{m}^{-2} \mathrm{~s}^{-1}$. Although the measured pressure drops more fluctuate compared to the numerical results, the calculated pressure drops in the sections P2 and P3 show good agreement with the experimental ones. The numerical result for P1 is under predicted, however, it is considered that the average discrepancies about $50 \mathrm{~Pa}$ are still tolerable.

Variation of the pressure drop in the case 2 (packed bed model B, $d_{\mathrm{p}}=0.596[\mathrm{~mm}], D_{\mathrm{p}}=4.48[\mathrm{~mm}]$, the diameter ratio 0.133 [-]) is shown in Fig. 4. In this case, the mass flux of fine particles is $0.064 \mathrm{~kg} \mathrm{~m}^{-2} \mathrm{~s}^{-1}$. Similar to the previous case, the comparison between numerical and experimental results is displayed. Also, in this case, the measured pressure drops are more fluctuated compared to the simulation results. However, the average value is matched between the experimental and numerical results. Thus, there is a good agreement between numerical and experimental results in all sections $\mathrm{P} 1, \mathrm{P} 2$, and $\mathrm{P} 3$.

Figure 5 shows the variations of the pressure drops obtained by the numerical simulation and the experiments in the case 3 (packed bed model B, $d_{\mathrm{p}}=0.596[\mathrm{~mm}], D_{\mathrm{p}}=3.68$ $\left.[\mathrm{mm}], d_{\mathrm{p}} / D_{\mathrm{p}}=0.162[-]\right)$. Mass flux of injected fine particles is the same as the case 2. The pressure drops of numerical results are in good agreement with the experimental results. From the validation, it can be observed, there is no remarkable increase of pressure drop for each case. As aforementioned before, in this current study total simulation time is $30 \mathrm{~s}$, thus the pressure increase is generally not significant. For case 1, packed bed model A (without the extra bed of $8 \mathrm{~mm}$ ), no remarkable differences in pressure distribution between $\mathrm{P} 1$ and $\mathrm{P} 2$ can be observed because the pressure gauge of $\mathrm{P} 1$ and $\mathrm{P} 2$ are located in the same packed bed with the diameter of $2.6 \mathrm{~mm}$. Furthermore, no significant increase in pressure drop also occurred because, as the pressure tap of P1 is located in the middle part of the transition area, the fine particles are accumulated in the lower half of transition area, while the amount of accumulated fine particles in the upper half is relatively small, which merely affected the increase of pressure drop.

Case 2 and 3 are using packed bed model B (with extrabed $8 \mathrm{~mm}$ ). In this case, P1 is located at the extra bed with the diameter of $8 \mathrm{~mm}$, while $\mathrm{P} 2$ is located in the packed bed with the diameter of $4.48 \mathrm{~mm}$, therefore the pressure reading at $\mathrm{P} 1$ of these cases is lower compare to the pressure reading at P2 and P3. From Fig. 4, the pressure drop for section P1 not show significant increase. This phenomenon mainly occurred because most of the part of P1 located in the extra $8 \mathrm{~mm}$ bed, with only half of the transition area is included, which caused only slightly increase of pressure drop is legible in this section. More significant pressure drop can be observed in P2 section, which is located in the transition area and the bed with diameter of $4.48 \mathrm{~mm}$, as the fine particles will penetrate from the transition area to the bed above.

\subsection{The Effect of Fines to Coarse Particle Diameter Ratio $\left(d_{\mathrm{p}} / D_{\mathrm{p}}\right)$}

The effect of diameter ratio (fines diameter to packed beads diameter $\left(d_{\mathrm{p}} / D_{\mathrm{p}}\right)$ on the permeability of fine particles in the packed bed is discussed in this section. Three diameter ratios, namely $0.133,0.149$ and $0.162[-]$, are set. The first case $\left(d_{\mathrm{p}} / D_{\mathrm{p}}=0.133[-]\right)$ consists of alumina beads and fines of $4.48 \mathrm{~mm}$ and $0.596 \mathrm{~mm}$. The second case $\left(d_{\mathrm{p}} / D_{\mathrm{p}}=\right.$ 0.149 [-]) consists of alumina beads and fines diameter of 2.60 and $0.388 \mathrm{~mm}$. The last case $\left(d_{\mathrm{p}} / D_{\mathrm{p}}=0.162[-]\right)$ is the case with beads and fines of $3.68 \mathrm{~mm}$ and $0.596 \mathrm{~mm}$ (they correspond cases 2,1, and 3 in the previous section). In these comparisons, the updraft gas velocity is set at 0.88 $\mathrm{m} \mathrm{s}^{-1}$ for all three cases. The fines mass flux for the first and third cases is $0.064 \mathrm{~kg} \mathrm{~m}^{-2} \mathrm{~s}^{-1}$ and $0.059 \mathrm{~kg} \mathrm{~m}^{-2} \mathrm{~s}^{-1}$ for the second case.

The variation of the vertical distribution of fine particles hold up with time under $d_{\mathrm{p}} / D_{\mathrm{p}}=0.133$ [-] is shown in Fig. 6. The packed bed is divided into 5 areas as shown in Fig. 1(a) (0-52, 52-197, 197-317, 317-437 and 437-582 mm in height), called as area $1,2,3,4$, and 5 , respectively. The fines hold up is defined as the volume of fine particles in the unit volume of packed bed in this paper. For packed bed model A, the transition area is located in area 2, on the top of diffusion bed or we called as area 1 (52-102 $\mathrm{mm}$ in height), and for packed bed model $\mathrm{B}$, the transition area is located in between area 2 and 3 on top of the extra bed (172-222 $\mathrm{mm}$ in height). In this condition, the fine particles are continuously injected at a constant rate from the diffuser. In the beginning, the hold up in the area 2 increases, then the hold up in the area 3 start to increase. Till $30 \mathrm{~s}$, the hold up in the area 2 continues to increases. The hold ups in the areas 2 and 3 reach about 0.099 and 0.048 vol\%, respectively. The hold ups in the upper parts increase with delay in order. This means that a part of the fine particles are stuck in the transition area and the remaining part flows to the upper part. It is considered that the vertical powder transfer and local sucking continue after this period, because the hold up distribution became uniform and the powder recovery ratio (the ratio particle flow-out rate from the top to the injection rate from the bottom) approached unity in the previous experimental study. ${ }^{11)}$

Figure 7 shows the snapshots of fines in the transition area of the packed bed under diameter ratio of $0.133[-]$. This figure was taken from the vertical cross section of the central area of the packed bed. At $t=3[\mathrm{~s}]$, only a small amount of fine particles can be seen in the middle height 


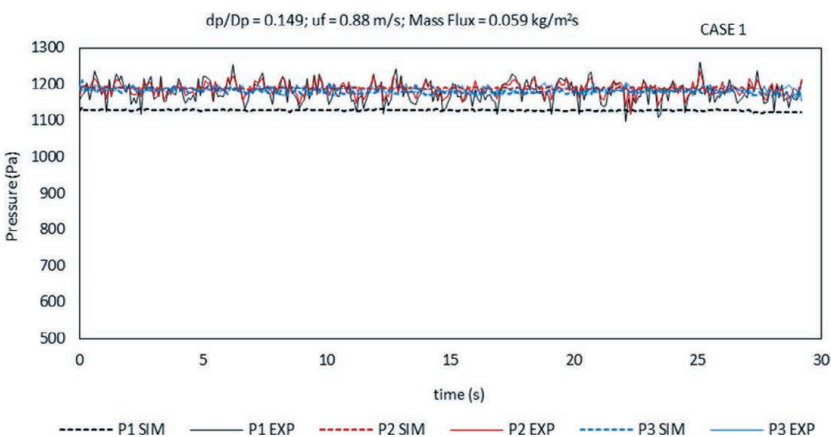

Fig. 3. Pressure comparison; experiment and simulation $d_{\mathrm{p}} / D_{\mathrm{p}}=$ $0.149[-]$.

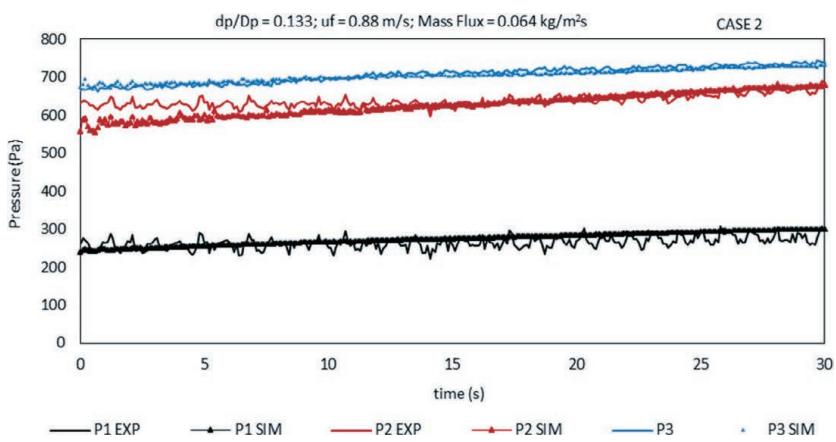

Fig. 4. Pressure comparison; experiment and simulation $d_{\mathrm{p}} / D_{\mathrm{p}}=$ $0.133[-]$.

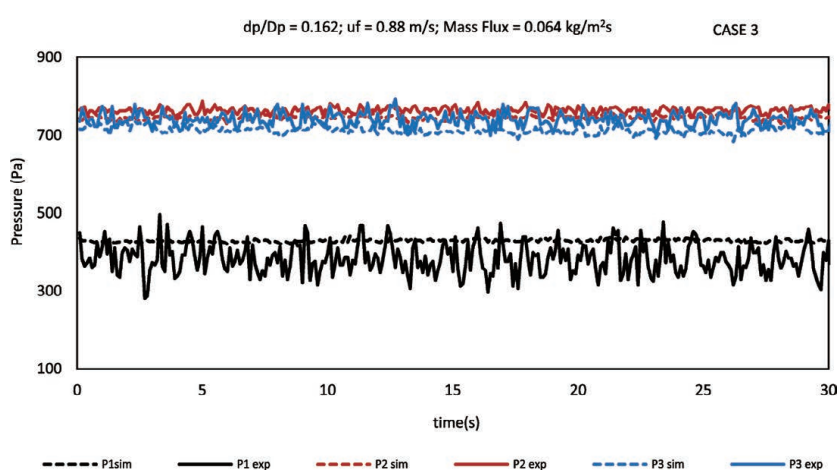

Fig. 5. Pressure comparison; experiment and simulation $d_{\mathrm{p}} / D_{\mathrm{p}}=$ $0.162[-]$.

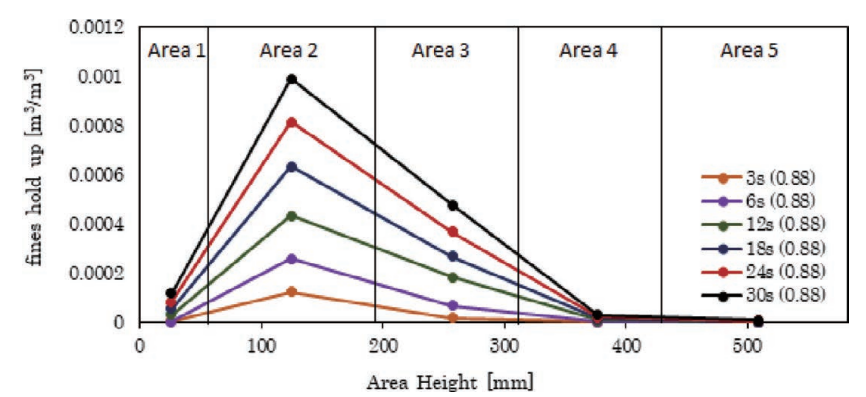

Fig. 6. Variation of fines hold up under $d_{\mathrm{p}} / D_{\mathrm{p}}=0.133[-]$ and $u_{\mathrm{f}}=$ $0.88\left[\mathrm{~m} \mathrm{~s}^{-1}\right]$.

of the transition zone. At $t=6[\mathrm{~s}]$, the fine particles reach to the upper area of the transition zone. In the following periods, the amount of the fine particles that are held in the packed bed gradually increases.

Figure 8 shows the variation of vertical distribution of

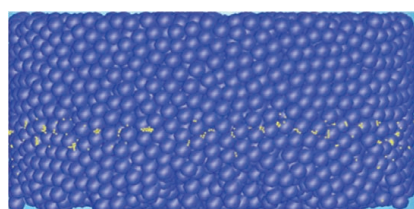

(a) $t=3 \mathrm{~s}$

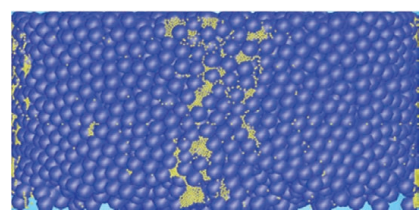

(c) $t=12 \mathrm{~s}$

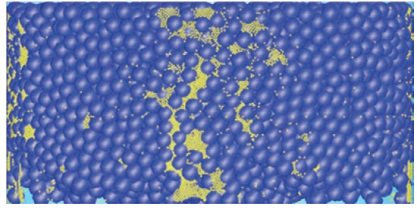

(e) $t=24 \mathrm{~s}$

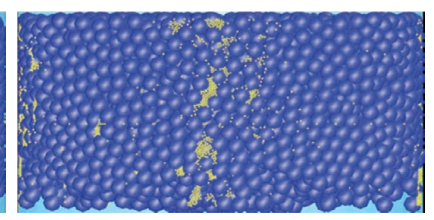

(b) $t=6 \mathrm{~s}$

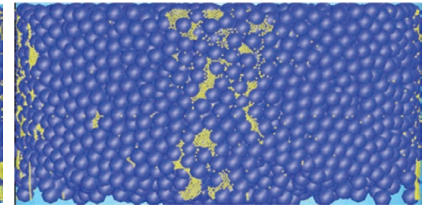

(d) $t=18 \mathrm{~s}$

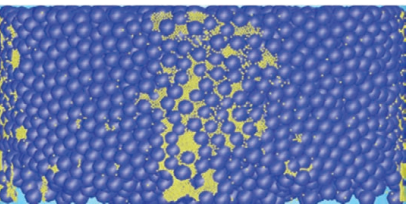

(f) $t=30 \mathrm{~s}$
Fig. 7. Fines hold up behavior under $d_{\mathrm{p}} / D_{\mathrm{p}}=0.133[-]$ condition.

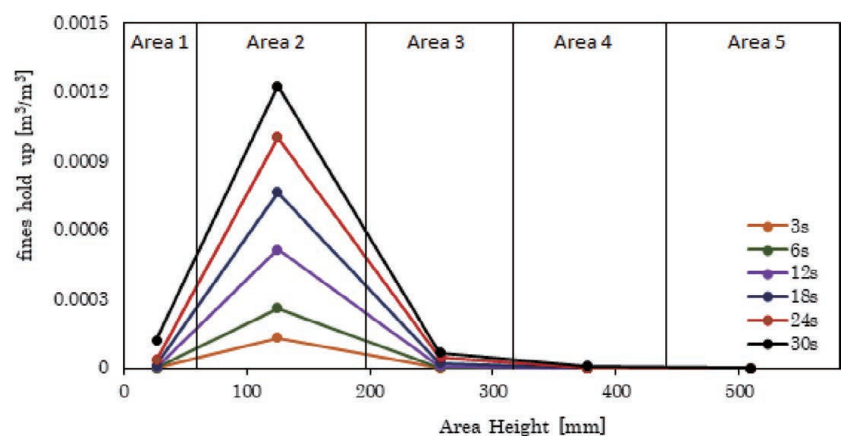

Fig. 8. Variation of fines hold up under $d_{\mathrm{p}} / D_{\mathrm{p}}=0.149[-]$ and $u_{\mathrm{f}}=$ $0.88\left[\mathrm{~m} \mathrm{~s}^{-1}\right]$

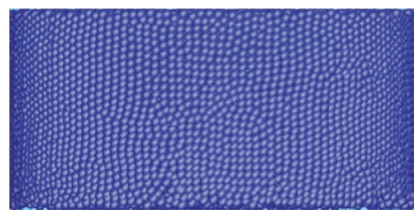

(a) $t=3 \mathrm{~s}$

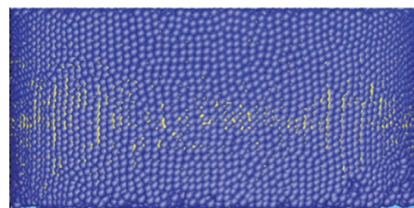

(c) $t=12 \mathrm{~s}$

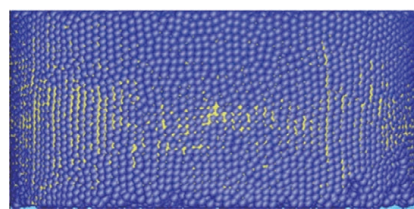

(e) $t=24 \mathrm{~s}$

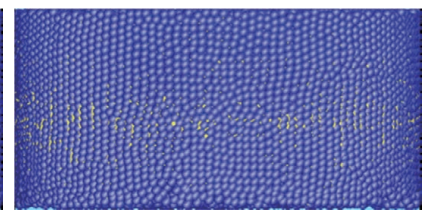

(b) $t=6 \mathrm{~s}$

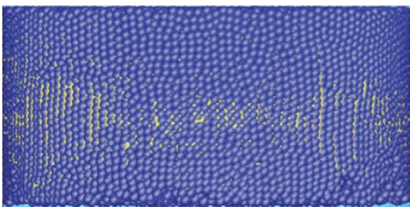

(d) $t=18 \mathrm{~s}$

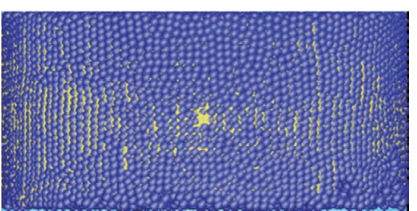

(f) $t=30 \mathrm{~s}$
Fig. 9. Fines hold up behavior under $d_{\mathrm{p}} / D_{\mathrm{p}}=0.149[-]$ condition.

fine particles hold up with time under $d_{\mathrm{p}} / D_{\mathrm{p}}=0.149$ [-]. Similar to the previous case, the fines hold up in the area 2 increases in the beginning. Although the hold up in the 
area 2 continues to increase, the hold up in the area 3 shows only a slight increase. Little hold up is observed in areas 4 and 5. The hold up in the area 2 reaches about $0.122 \mathrm{vol} \%$ that is higher than the previous case while the area 3 shows only about $0.0066 \mathrm{vol} \%$ at $30.0 \mathrm{~s}$. This result indicates that most of the injected fine particles are trapped in the area 2 and only little particles can pass this area to the upper area. In the previous experimental study, a negligible amount of powder flowed out to the top of the packed bed under the same diameter ratio condition. ${ }^{11)}$

Figure 9 shows the snapshots of fines hold up in the packed bed under $d_{\mathrm{p}} / D_{\mathrm{p}}=0.149$ [-]. At $t=3$ [s], a lot of small clusters are formed in the middle of the transition area. In each cluster, the fine particles lined vertically between the alumina beads in this packing structure. With time progresses, the number of clastters increases stuck and their shapes are elongated. At $t=30[\mathrm{~s}]$, a few clusters reach the upper part of the transition area. This behavior means that most of fine particles are stuck in the first half of the transition area, and the latter half, the sucked particles increase and a small portion of the injected particles transported to the upper area, as shown in Fig. 8.

Figure 10 shows the variation of the vertical distribution of fine particles hold up with time under $d_{\mathrm{p}} / D_{\mathrm{p}}=0.162[-]$. Similar to the $d_{\mathrm{p}} / D_{\mathrm{p}}=0.149[-]$ case, the hold up in the area 2 mainly increases. Substantially no increase in the fines hold up also occurs in the upper areas. The hold up in the area 2 is about $0.162 \mathrm{vol} \%$ at $30.0 \mathrm{~s}$.

Figure 11 shows the snapshots of fines held up in the packed bed under $d_{\mathrm{p}} / D_{\mathrm{p}}=0.162[-]$. Similar to the previous case of $d_{\mathrm{p}} / D_{\mathrm{p}}=0.149[-]$, the injected particles are stuck in the transition area, especially in the bottom part of this area. Although the accumulation area expands with time progresses, it only reaches up to the middle height of the transition area. Therefore, the particles are unable to transport to the upper areas.

In the minimum and the maximum particle diameter ratio cases, namely $d_{\mathrm{p}} / D_{\mathrm{p}}=0.133$ and $0.162[-]$, the fine diameter, the mass flux, and the gas velocity are common. The fines behaviors, however, completely different. In the former, the fine particle can pass through the packed bed, while all the fine particles are accumulated in the bed in the latter case. Furthermore, the particles in $d_{\mathrm{p}} / D_{\mathrm{p}}=0.149[-]$ case can penetrate up to the middle of the transition area while the particles in $d_{\mathrm{p}} / D_{\mathrm{p}}=0.162$ [-] can reach to only the bottom part of the bed, even some conditions are different. From these results, the diameter ratio has a great effect on the permeation of fine particles through the packed bed. This supports the conclusion of previous study ${ }^{11)}$ that the critical diameter ratio for blockage formation is $0.12[-]$ while the fine particles pass through the bed under $d_{\mathrm{p}} / D_{\mathrm{p}}=0.133[-]$ in this work. The difference could be the packing conditions in the experiments and the numerical simulation.

\subsection{Effect of Gas Superficial Velocity}

The effect of gas superficial velocity on the fine particle permeation behavior is discussed. The variations of fine particle hold up obtained under the gas superficial velocity of 1.06 and $1.24 \mathrm{~m} \mathrm{~s}^{-1}$ are shown in Figs. 12 and 13. The diameter ratio is $0.133[-]$, and the fines mass flux is 0.064 $\mathrm{kg} \mathrm{m}^{-2} \mathrm{~s}^{-1}$. Both cases show similar variations of the hold up to the result under the superficial gas velocity of 0.88 $\mathrm{m} \mathrm{s}^{-1}$ shown in Fig. 6. It can be observed there are no significant change of fine particles hold ups for both cases $\left(u_{\mathrm{f}}=1.06 \mathrm{~m} \mathrm{~s}^{-1}\right.$ and $\left.1.24 \mathrm{~m} \mathrm{~s}^{-1}\right)$, compare to previous case $\left(u_{\mathrm{f}}=0.88\left[\mathrm{~m} \mathrm{~s}^{-1}\right]\right)$

The variations of the fine powder hold up in areas 2, 3, 4 and 5 are shown in Fig. 14. In the figure, the variations under the gas superficial velocities of $0.88,1.06$ and 1.24 $\mathrm{m} \mathrm{s}^{-1}$ are displayed. The fines hold ups show similar monotonical increase regardless of the gas velocity and there are no significant differences among the three velocities can be observed. According to the previous study, the fraction of fines holdup decreases with the increase of gas velocity when the mass flux of fines is kept constant and hence, the pressure drop curve should have a tendency to approach the value of pure gas with increasing gas velocity. ${ }^{10)}$ This means with the increase of gas velocity, the fine particles will be easily transported to the upper area because of higher updraft driving force. However, this phenomenon is only consistent if the particle diameter ratio is small enough or the gap fine particle and flow channel aperture is big enough. Moreover, it should be noticed that in this section, the effect of gas superficial velocities are observed under $d_{\mathrm{p}} / D_{\mathrm{p}}=0.133[-]$, where the particle diameter ratio already exceeds the critical diameter ratio of $d_{\mathrm{p}} / D_{\mathrm{p}}=0.12$ $[-]^{11)}$ Thus it can be concluded that the change of gas superficial velocity becomes less significant when $d_{\mathrm{p}} / D_{\mathrm{p}}$ already exceeds the critical diameter ratio.

\subsection{Fraction of Local Blockage}

In the previous paper by Natsui et al., ${ }^{18)}$ fine particles were injected in pulse-wise feeding, where the constant volume of fine particles was generated in the packed bed. Because of the constant volume of fine particles in their numerical approach, the gas flow becomes constant and uniform, where even heavily concentrated powder always received upward drag force and move upward little by little. Contrarily, in this present study, the actual behavior of gas flow is expected to be able to obtain because of continuous feeding. When the fine particles are injected continuously and going through the transition area, they will go together with the gas flow through the diffuser bed and extra bed. When the fine particles reached the bottom part of the transition area, with the gas flow they will avoid the heavily concentrated area or for instant, it will pass through the voids that exist within the transition area. Then, the voids in the transition area are eliminated and filled by the fine particles and change the gas flow patterns.

Figure 15 shows the void fractions and the contour of absolute gas velocity $\left(u_{\mathrm{f}}=0.88 \mathrm{~m} \mathrm{~s}^{-1}\right)$ under $d_{\mathrm{p}} / D_{\mathrm{p}}=0.133$ [-] at $t=0[\mathrm{~s}]$ and $t=30[\mathrm{~s}]$, located in the transition area of packed bed model B. From Fig. 15(a) at $t=0$ [s], it can be observed that the voids mainly exist in the middle section of the transition area, with several spots of high void concentration (red spots), can be observed. Some voids also scattered randomly and also connected around the transition area. As a comparison, Fig. 15(c) shows the contour of absolute velocity at $t=0[\mathrm{~s}]$. It can be seen that the gas flow pattern is following a similar pattern as voids fraction where the gas flow is mainly concentrated in the middle section of the transition area. Furthermore, high concentration gas 
flow also can be observed in the same location where the high void concentration (red spots) exists. Similar to void fractions that scattered and connected around the transition area, the gas flow also being scattered and connected in the same areas. In Fig. 15(b) at $t=30$ [s], the high void concen-

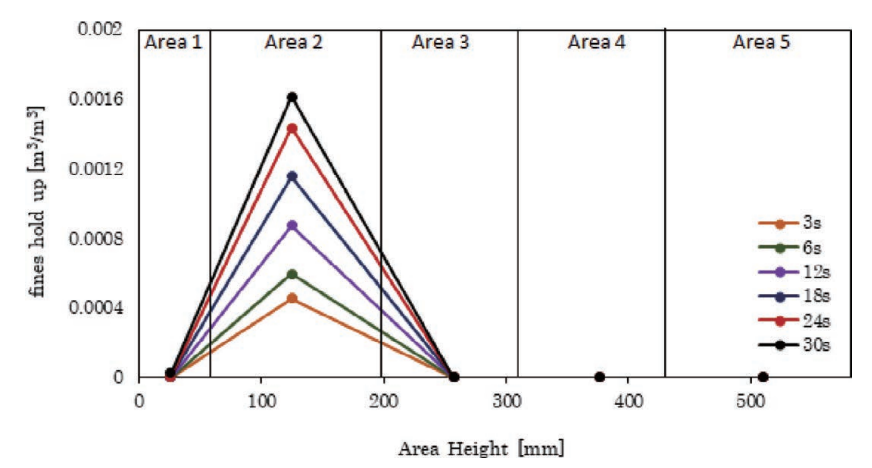

Fig. 10. Variation of fines hold up under $d_{\mathrm{p}} / D_{\mathrm{p}}=0.162[-]$ and $u_{\mathrm{f}}=$ $0.88\left[\mathrm{~m} \mathrm{~s}^{-1}\right]$.

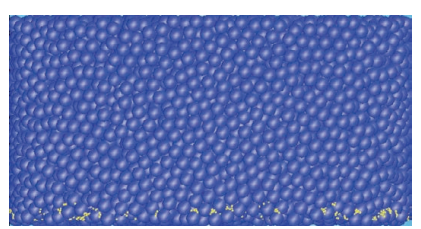

(a) $t=3 \mathrm{~s}$

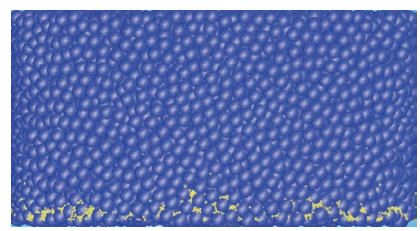

(c) $t=12 \mathrm{~s}$

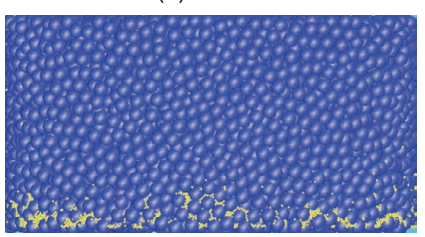

(e) $t=24 \mathrm{~s}$

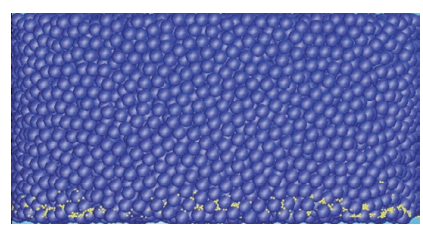

(b) $t=6 \mathrm{~s}$

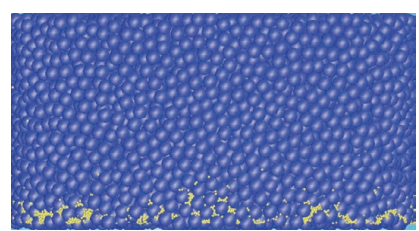

(d) $t=18 \mathrm{~s}$

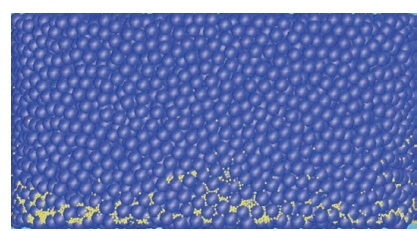

(f) $t=30 \mathrm{~s}$
Fig. 11. Fines hold up behavior under $d_{\mathrm{p}} / D_{\mathrm{p}}=0.162[-]$ condition. trations are already eliminated and the scattered voids also become less connected, indicates the fine particles alreadyed filled the voids. From Fig. 15(d), the contour of absolute gas velocity at $t=30[\mathrm{~s}]$ is also in a good agreement with the voids patterns. It shows that even though the gas flow

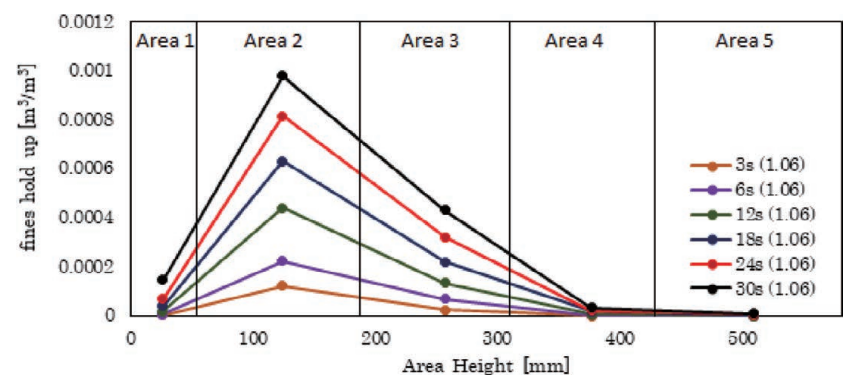

Fig. 12. Fines hold up; $d_{\mathrm{p}} / D_{\mathrm{p}}=0.133 ; u_{\mathrm{f}}=1.06 \mathrm{~m} \mathrm{~s}^{-1}$.

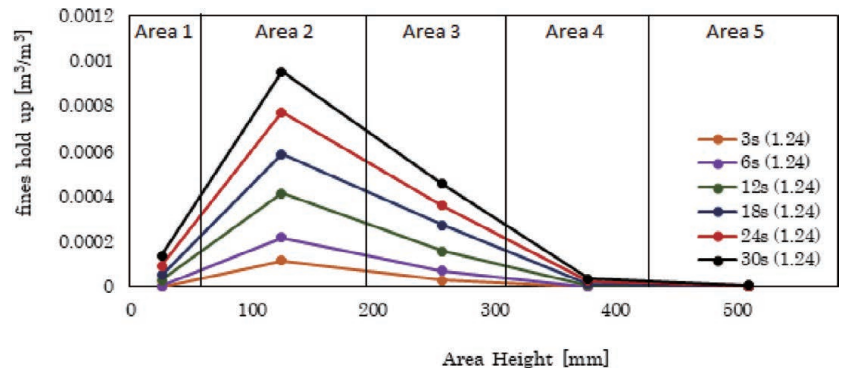

Fig. 13. Fines hold up; $d_{\mathrm{p}} / D_{\mathrm{p}}=0.133 ; u_{\mathrm{f}}=1.24 \mathrm{~m} \mathrm{~s}^{-1}$.

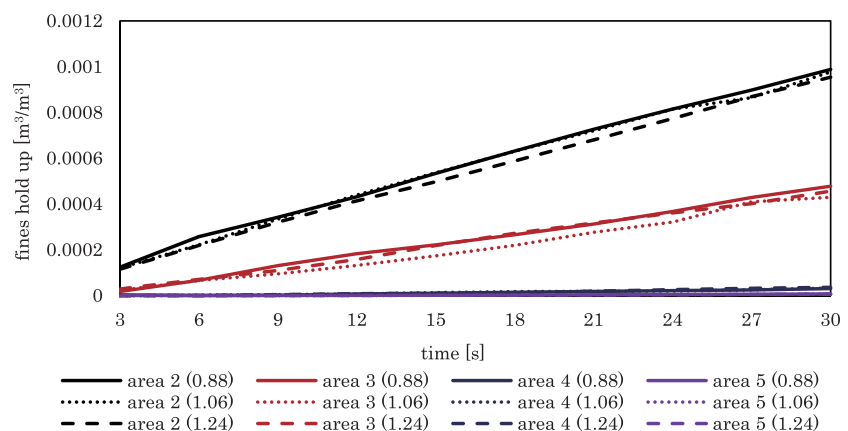

Fig. 14. Fines hold up of $d_{\mathrm{p}} / D_{\mathrm{p}}=0.133$ [-] with various superficial gas velocities.

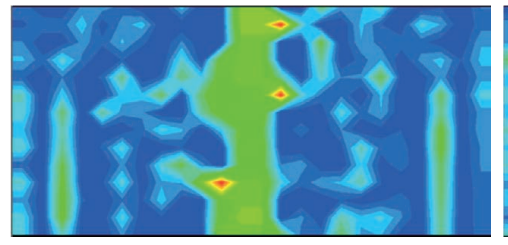

(a) Void fraction $t=0 \mathrm{~s}$

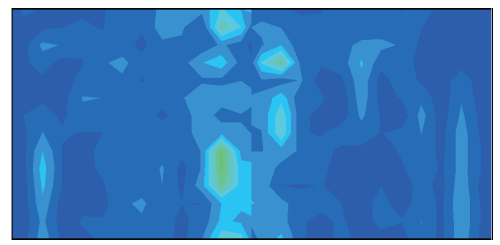

(c) absolute velocity $t=0 \mathrm{~s}$

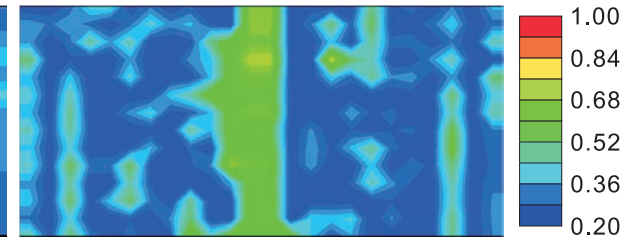

(b) void fraction $t=30 \mathrm{~s}$

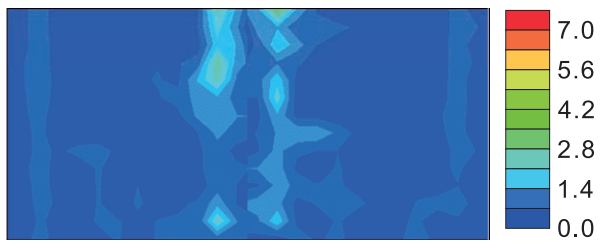

(d) absolute velocity $t=30 \mathrm{~s}$

Fig. 15. Void fraction and abs velocity distribution under $d_{\mathrm{p}} / D_{\mathrm{p}}=0.133[-]$ condition. 
is still concentrated in the middle section of the transition area, but it becomes less concentrated, similar to void patterns. This phenomenon indicates that gas flows avoiding the heavily concentrated area or become weak in highly concentrated area.

\section{Conclusion}

Numerical simulation of fines permeability inside the packed bed is already been done. In this simulation fine particles are injected continuously every second, mimicking the experimental approach by Takahashi et al. ${ }^{11)}$ The effect of particle diameter ratios and updraft gas velocities to fines permeability were analyzed. The following conclusions are as follows.

(1) Comparison between numerical and experimental approaches showed a good agreement and high accuracy from the pressure distribution. Some differences mostly occurred because of the physical situation in the experimental conditions such as particle motion, sphericity, and pressure gauge reading that neglected in numerical approach.

(2) The particle diameter ratio become the major cause for particle restrained in the transition area. Larger particle ratio resulted in higher particle hold up in area 2 while no significant increase of fines hold up in the upper area. Fine particles tend to concentrate at the bottom of the packed bed owing to an increase in their diameter ratio. From a broader scale point of view, the height of fine particles can penetrate vertically is changes according to the particle diameter ratio.

(3) There are no significant change in fines fraction transported to upper area due to the change of gas velocity. This phenomenon more likely because the diameter ratio already exceeds the critical diamater ratio proposed by previous experimental study. ${ }^{11)}$

(4) The change of void fraction actual pattern of gas flow can be obtained in this simulation. As the time lapsed, voids fraction are decreasing because being filled by fine particles. it also can be shown that the gas flow is avoiding the heavily concentrated area or become very weak in the low void fraction area.

\section{Acknowledgment}

A part of this work was performed under the Cooperative Research Program of "Network Joint Research Center for Materials and Devices."

\section{REFERENCES}

1) Ministry of the Environment, Japan: National Greenhouse Gas Inventory Report of Japan, National Institute for Environmental Studies, Ministry of the Environment, Japan Ibaraki, (2013), 2. 4, 3. 2.

2) T. Ariyama and M. Sato: ISIJ Int., 46 (2006), 1736.

3) N. Hidaka, J. Iyama, T. Matsumoto, K. Kusakabe and S. Morooka: Powder Technol., 45 (1998), 265.

4) N. Hidaka, T. Matsumoto, K. Kusakabe and S. Morooka: Korean J. Chem. Eng., 16 (1999), 852.

5) N. Hidaka, T. Matsumoto, K. Kusakabe and S. Morooka: J. Chem. Eng. Jpn., 32 (1999), 197.

6) N. Hidaka, T. Matsumoto, K. Kusakabe and S. Morooka: J. Chem. Eng. Jpn., 33 (2000), 152.

7) X. F. Dong, D. Pinson, S. J. Zhang, A. B. Yu and P. Zulli: Powder Technol., 149 (2004), 1.

8) J. Chen, T. Akiyama, H. Nogami and J. Yagi: ISIJ Int., 34 (1994), 133.

9) T. S. Pham, D. Pinson, A. B. Yu and P. Zulli: Chem. Eng. Sci., 54 (1999), 5339.

10) S. Koichiro, M. Shimizu, S. Inaba, R. Takahashi and J. Yagi: ISIJ Int., 31 (1991), 434.

11) H. Takahashi, H. Kawai, T. Kondo and M. Sugawara: ISIJ Int., 51 (2011), 1608.

12) K. W. Chu and A. B. Yu: Powder Technol., 179 (2008), 104.

13) X. F. Dong, S. J. Zhang, D. Pinson, A. B. Yu and P. Zulli: Powder Technol., 149 (2004), 10.

14) B. H. Xu, A. B. Yu, S. J. Chew and P. Zulli: Powder Technol., 109 (2000), 13.

15) S. Matsuhashi, H. Kurosawa, S. Natsui, T. Kon, S. Ueda, R. Inoue and T. Ariyama: ISIJ Int., 52 (2012), 1990.

16) H. Nogami, P. R. Austin, J. Yagi and K. Yamaguchi: ISIJ Int., 44 (2004), 500.

17) S. Kikuchi, T. Kon, S. Ueda, S. Natsui, R. Inoue and T. Ariyama: ISIJ Int., 55 (2015), 1313.

18) S. Natsui, S. Ueda, H. Nogami, J. Kano, R. Inoue and T. Ariyama: Chem. Eng. Sci., 71 (2012), 274. 